\title{
Management of Impacted Transmigrated Mandibular Canine Associated With Dentigerous Cyst- A Surgical Approach
}

\author{
Akhilesh Kumar Singh*, Naresh Kumar, Nitesh Mishra, Shankar Singh and Shreya Singh \\ Department of Oral \& Maxillofacial Surgery, Banaras Hindu University, India
}

Submission: October 30, 2017; Published: May 07, 2018

*Corresponding author: Akhilesh Kumar Singh, Department of Oral \& Maxillofacial Surgery, Faculty of Dental Sciences, Banaras Hindu University, Varanasi, India, Tel: 8756837388; Email: georgianaks@gmail.com

\section{Abstract}

Transmigration of impacted canine is an uncommon phenomenon in which unerupted canine crosses the midline. Sometimes this condition may also be associated with any pathology or cystic degeneration and in such a case surgical extraction along with the enucleation of cyst is the preferred treatment modality. The present study discusses a case of 12 -year-old adolescent male with similar condition managed with surgical removal of tooth and cyst enucleation.

Keywords: Transmigration; Mandibular canine; Impacted canine; Dentigerous cyst

\section{Introduction}

Transmigration is an uncommon phenomenon in which unerupted tooth crosses the midline. Ando et al. [1] first uses the term "Transmigration" [1]. Transmigration is typically found in mandibular canines but may occur rarely in maxillary canine [2]. Transmigrated canines usually remain asymptomatic although follicular cyst formation and chronic infection with fistula formation may occur $[3,4]$. They may remain impacted or erupt ectopically. In some cases transmigrating teeth may cause pressure resorption of roots or tilting of teeth. Transmigrated mandibular canine mostly occur unilaterally but some cases of bilateral occurrence also had been reported. It is more frequently found in females as compared to males in the ratio of 1.6:1 [5,6]. Due to its unfavorable position, repositioning by orthodontic means is rarely indicated and since transmigrated mandibular canine may also develop pathology associated with it, transalveolar extraction is mostly indicated.

\section{Case Report}

A 12-year-old adolescent male reported with a chief complaint of malaligned lower front teeth. Intraoral examination revealed retained right deciduous mandibular canine and absence of right mandibular permanent canine (Figure 1). Orthopantamogram and lateral cephalogram showed a horizontally placed impacted mandibular canine of right side crossing the midline with well defined radiolucency surrounding the coronal portion (Figure 2 \& 3). The location of impacted canine was just above the inferior border of mandible crossing the midline up to level of contralateral canine. By analyzing all the clinical and radiological findings, a provisional diagnosis of dentigerous cyst associated with transmigrated impacted right mandibular canine is established. Orthodontic consultation was done regarding retrieval but denied by the specialists. Patient was counseled about the treatment and complications. After routine blood investigations, patient was planned for transalveolar extraction along with enucleation of cyst through crevicular approach under local anaesthesia. After preoperative preparation, bilateral inferior alveolar nerve block given and exposure was done from canine to canine through crevicular incision and releasing from both the sides. On exposure a hard bony swelling present over the symphysis region (Figure 4). The overlying bone was removed and crown expose (Figure 5) and then sectioning was done to remove it. After removal of crown, the root is also retrieved with the help of elevator and cystic lining enucleated (Figure 6). Curettage of remaining cavity was further done. Soft tissue closure was achieved in single layer with 3-0 silk suture (Figure 7). Now the patient is under regular follow up.

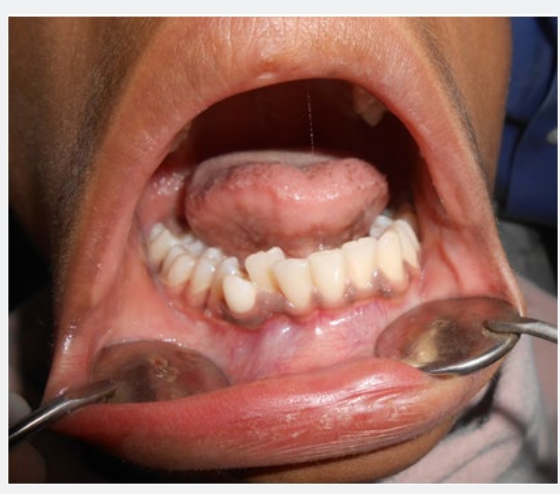

Figure 1: Intraoral photograph showing crowding of mandibular anterior teeth and retained deciduous right mandibular canine. 


\section{Advances in Dentistry \& Oral Health}

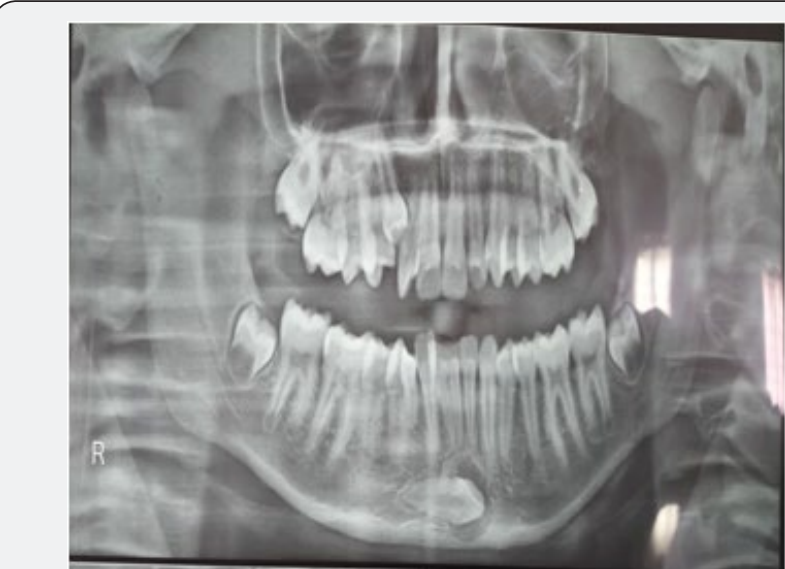

Figure 2: Orthopantomogram showing horizontally placed transmigrated impacted mandibular right canine.

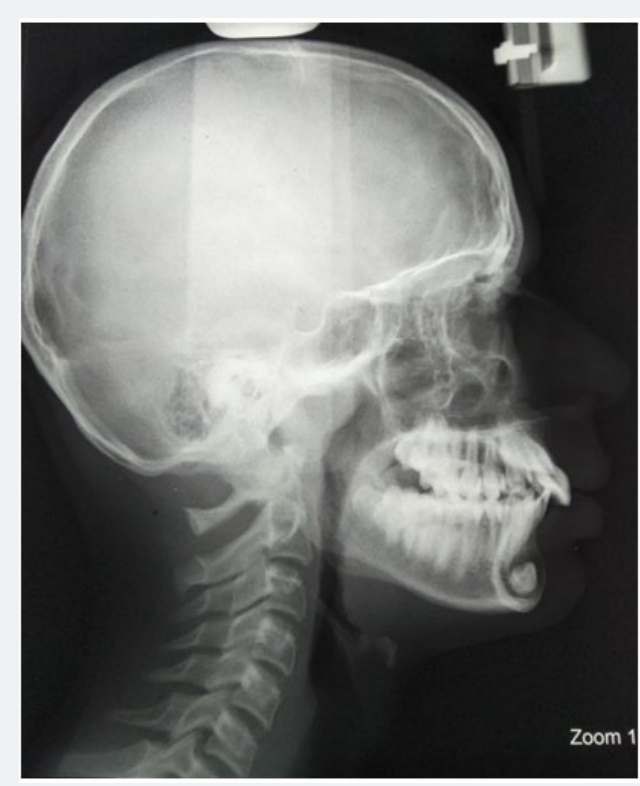

Figure 3: Lateral Cephalogram showing impacted tooth near the inferior border of the mandible.

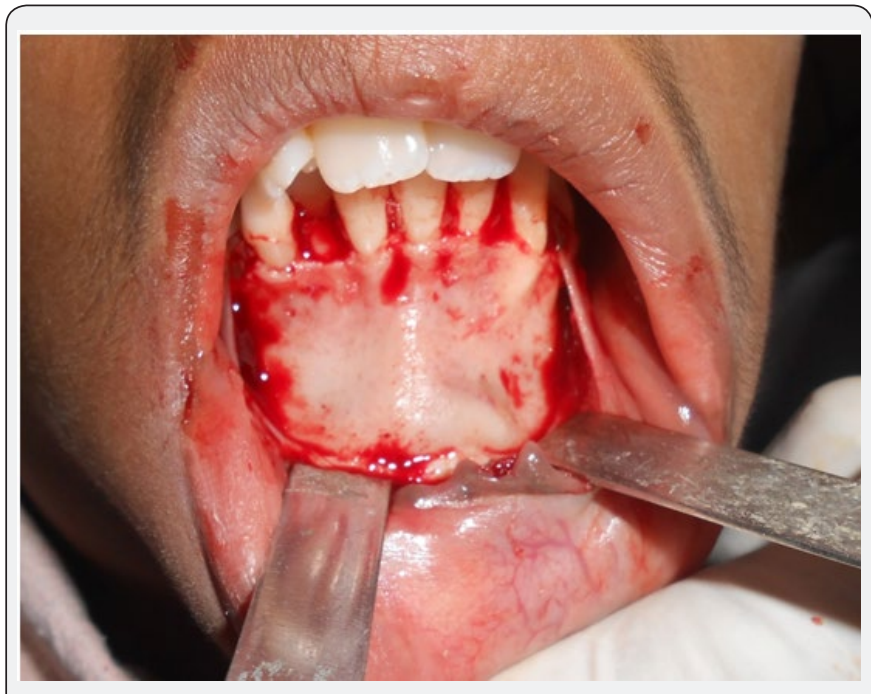

Figure 4: Photograph showing the exposed anterior mandible.

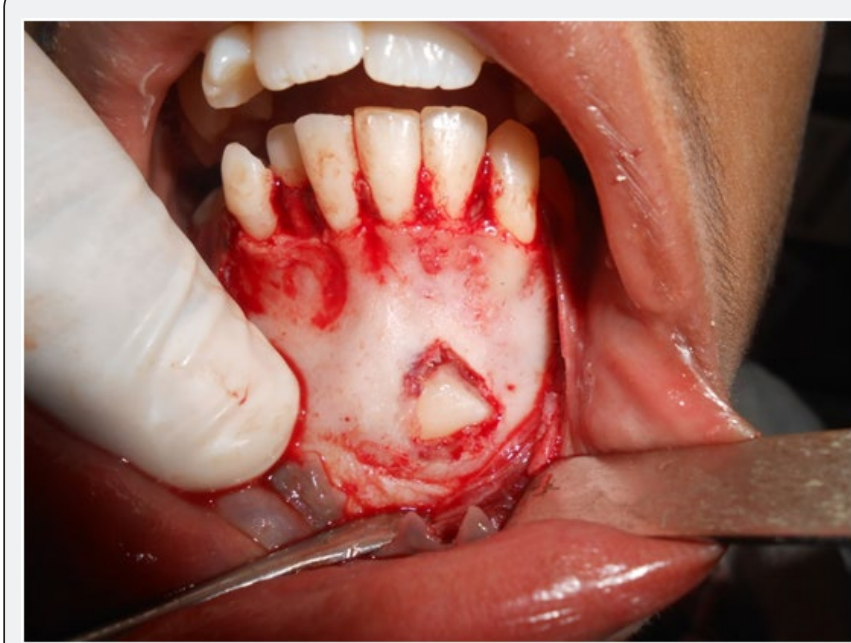

Figure 5: Photograph showing the exposed coronal portion of mandibular right canine.

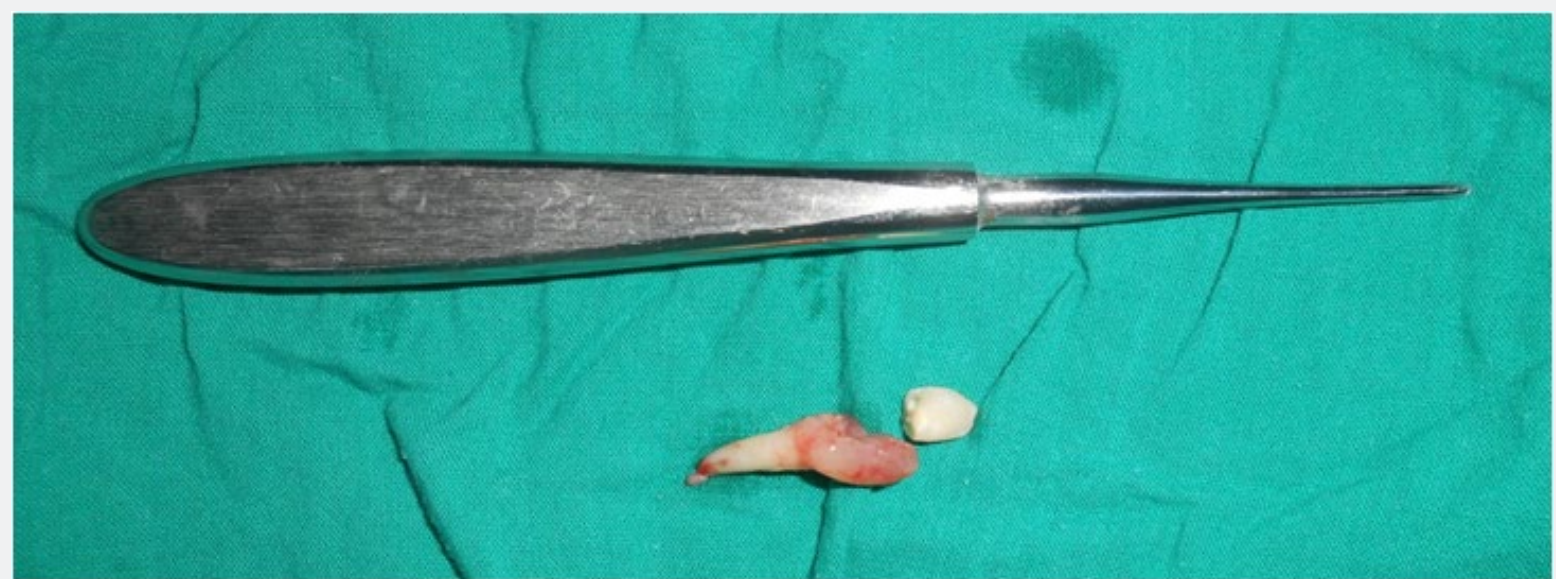

Figure 6: The tooth specimen after removal. 


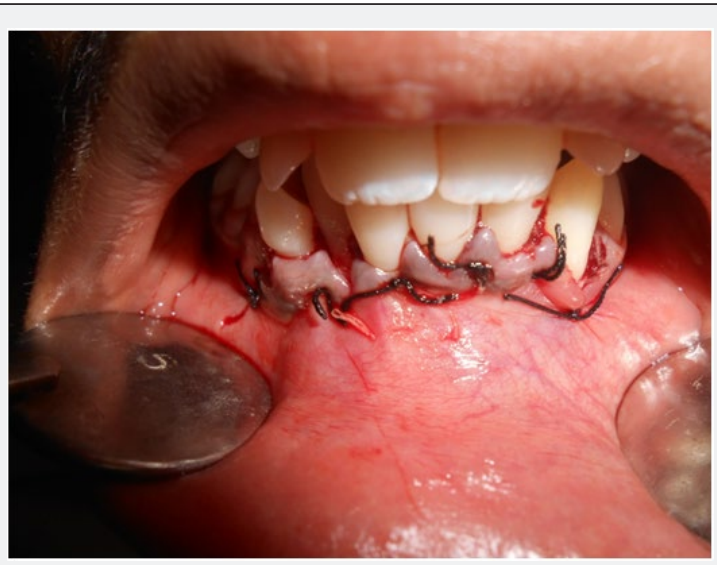

Figure 7: The post operative pic with sutures in place.

\section{Discussion}

Transmigration of canine is an uncommon phenomenon affecting mostly left side of mandible with its incidence higher in females. Tarsitano et al. defined transmigration as a phenomenon in which an unerupted mandibular canine migrates, crossing the midline [7,8]. Javid [3] expanded the definition to include the cases in which more than half of the tooth had passed through the midline [8]. Joshi \& Auluck et al. [9,10] suggested that the tendency of canine to cross the midline suture is a important consideration than the actual distance of migration after crossing the midline $[9,10]$. Little is known about the etiology of transmigration however various etiologies are suggested such as premature loss or retention of deciduous canines, long path of eruption of canine, trauma, tumours, odontomas, no anatomical restriction in midline of mandible and genetic predisposition. Marks and Schroeder suggested that a regional disturbance in the dental follicle might lead to local defective osteoclastic function with an abnormal eruption pathway being formed [11]. Virchi \& Franchi [12] suggested that, proclination of lower incisors, increased axial inclination of the unerupted canine and an enlarged symphyseal cross-sectional area of the chin may be favorable conditions for transmigration [12].

Clinical findings associated with transmigration of the canines include absence of mandibular canines in the dental arch or abnormal retention of the mandibular primary canine. A few cases also involved congenitally missing mandibular lateral incisors and mandibular premolars. Transmigration is mainly diagnosed with help of radiographic evaluation, which is primarily based on the panoramic radiograph. Mostly transmigrated canines are asymptomatic, although follicular cyst formation and chronic infection with fistula formation have been reported. The following criteria were used to describe transmigration patterns: inclination of the long axis of the canine, relationship of the canine and, in particular, the crown with the midline, adjacent teeth and contralateral erupted canine. The transmigrated teeth were classified based on their migratory pattern and the final position within the jaw when diagnosed [13]. a) Type 1: Canine positioned mesio-angularly across the midline within the jaw bone, labial or lingual to anterior teeth, and the crown portion of the tooth crossing the midline.

b) Type 2: Canine horizontally impacted near the inferior border of the mandible below the apices of the incisors.

c) Type 3: Canine erupting either mesial or distal to the opposite canine.

d) Type 4: Canine horizontally impacted near the inferior border of the mandible below the apices of either premolars or molars on the opposite side.

e) Type 5: Canine positioned vertically in the midline (the long axis of the tooth crossing the midline) irrespective of eruption status.

According to above- mentioned classification, our case shows "Type 2" pattern of transmigration. Surgical removal, transplantation, radiographic follow-up and surgical exposure with orthodontic treatment are suggested treatment options. Here surgical extraction is the treatment of choice keeping in mind the position of nerve and position of root apices with respect to transmigrated mandibular canine. It should also be noted that innervations of transmigrated is from the original side. Hence, an anesthesia of the originating side is essential during surgical treatment.

\section{Conclusion}

The presence of an over-retained mandibular canine should always be investigated both clinically and radio graphically to rule out the condition. Many treatment modalities have been suggested but when transmigrated canine associated with a pathologic or any cystic degeneration, surgical management is one of the most favored treatments in literatures.

\section{References}

1. Ando S, Aizaea K, Nakashima T, Sanka Y, Shimbo K, et al. (1964) Transmigration process of impacted mandibular cuspid. J Nihon Univ Sch Dent 6: 66-71.

2. Aydin U, Yilmaz HH (2003) Transmigration of impacted canines. Dentomaxillofac Radiol 32(3): 198-200.

3. Javid B (1985) Transmigration of impacted mandibular cuspids. Int J Oral Surg 14(6): 547-549.

4. Camilleri S, Scerri E (2003) Transmigration of mandibular canines - A review of the literature and a report of five cases. Angle Orthod 73(6): 753-762.

5. Peck S (1998) On the phenomenon of intraosseous migration of nonerupting teeth. Am J Orthod Dentofacial Orthop 113(5): 515-517.

6. Singh S, Singh AK, Sharma NK, Chaturvedi TP (2017) Transmigration of impacted mandibular canine with the development of dentigerous cyst: Surgical extraction or orthodontic alignment? J Dent Allied Sci 6(1): 32-34.

7. Umashree N, Kumar A, Nagaraj T (2013) Transmigration of mandibular canine. Case Rep Dent 2013: 1-7.

8. Kuftinec MM, Shaphira Y, Nahlieli O (1995) Bilateral transmigration of impacted mandibular canines. J Am Dent Assoc 126(7): 1022-1024. 
9. Joshi MR (2001) Transmigrant mandibular canines: A record of 28 cases and a retrospective review of the literature. Angle Orthod 71(1): 12-22.

10. Auluck A, Nagpal A, Setty S, Pai KM, Sunny J (2006) Transmigration of impacted mandibular canines - Report of 4 cases. J Can Dent Assoc 72(3): 249-252.

11. Marks SCJ, Schroeder HE (1996) Tooth eruption: theories and facts. Anat Rec 245(2): 374-393.
12. Vichi M, Franchi L (1991) The transmigration of the permanent lower canine. Minerva Stomatol 40(9): 579-589.

13. Mupparapu M (2002) Patterns of intra-osseous transmigration and ectopic eruption of mandibular canines: Review of literature and report of nine additional cases. Dentomaxillofac Radiol 31(6): 355-360.

This work is licensed under Creative

\section{Your next submission with Juniper Publishers} will reach you the below assets

- Quality Editorial service

- Swift Peer Review

- Reprints availability

- E-prints Service

- Manuscript Podcast for convenient understanding

- Global attainment for your research

- Manuscript accessibility in different formats

( Pdf, E-pub, Full Text, Audio)

- Unceasing customer service

Track the below URL for one-step submission https://juniperpublishers.com/online-submission.php 